\title{
Role of Explicit Knowledge Management and Reuse in Higher Educational Environment
}

\author{
Sanjiv Sharma \\ NIMS University, Jaipur, Rajasthan \\ Agra, India
}

\author{
O.K. Harsh \\ Pro Chancellor (Addl) \\ Glocal University, \\ Delhi-Yamunotri Rd, State Highway 57, \\ Mirzapur Pole, Saharanpur-247122, India
}

\begin{abstract}
Role of knowledge management and knowledge reuse has been investigated analytically in higher educational environment using Nonaka \& Takeuchi and Harsh models. It has been observed that in three dimensional environment knowledge management and reuse together play key role for students and faculty both if these could be appropriately exploited. A comprehensive system can be built which can benefit both students and faculty in wider areas of their respective knowledge management. Special benefits of knowledge reuse may be seen if we could treat knowledge reusability as an independent quantity along with explicit and tacit knowledge. Current model reveals analytically that knowledge reusability may boost the operative knowledge in an educational organization and may have its sovereign reality. Present work may be also helpful to manage knowledge during software reuse and associated actions.
\end{abstract}

Keywords-Knowledge Management; Higher Education; Software Engineering; Knowledge Reuse; Harsh Model

\section{INTRODUCTION}

The managerial knowledge conception theory was advanced by Nonaka and his colleagues [1-5, 6]. This was realized through the investigation of information formation in renovating companies [7, 8]. It is not frequent evident in knowledge history that in what way and why knowledge formation take place? What are the association amid the current knowledge and the knowledge reusability of that system in an educational environment? It is an acceptable fact that Nonaka's [1-5] concept of organizational knowledge advancement demonstrates utmost vital theory in the history of knowledge organization. Though, work of Gourlay [9] suggests that pragmatic foundation for the model is an inadequate.

Work of Jorna [10] states that the four stages of knowledge formation in earlier work of Nonaka et al. model [1-5] will indicate an alteration in sign of knowledge as a result of conversion of knowledge from its one form to another. This warrant a "semiotic framework for dealing with sign is required" [9]. Thorough case studies and clarification of above Nonaka et al. [1-3] model has been furnished by Gourlay [9], who observed several unacceptable facts about the Nonaka's model. However, so far SECI model remains the most acceptable and unique model in the vast research of knowledge management.

It is an astounding point that in-spite of great care to knowledge formation and allocation theories and matters, the reusable knowledge has not been considered openly in the
Nonaka model [1-5] particularly for the educational environment. This suggests that a further study to refine this model in the wake of knowledge reusability in an educational environment may be an important area of research.

Knowledge management and reuse in advanced education has been mounting with fast proportion as a result of enhancement of huge number of higher educational establishments. Moreover, the necessity of enhancement in quality of education and need of saving time has been becoming an important aspect in technological environment.

In higher educational institutions, knowledge management and knowledge reuse as well as modernization of knowledge and its sharing is vital issues. These are measured similar to the business issues and cannot advance only the quality of knowledge while at the same time can save the required efforts provided if we could adapt and adopt the existing knowledge. According to Roffe [11] such processes are responsible for creating the resources employed by educational institutions for the advancement of their quality [12].

Higher educational institutions should require tactical policies to inspire groundbreaking knowledge management mechanisms. Some of the examples are allocations of knowledge from specialists to trainees [13] and distribution of utmost suitable information to trainees which are vigorous ideas for the purpose of knowledge management [14].

Work of Grant [15] split knowledge reuse models "into those that focus on knowledge acquisition (or replication) and those that focus on knowledge integration" while work of Szulanski [28] recommended a sketch of "knowledge reuse as replication".

\section{OBJECTIVE AND SCOPE}

The key aim of present work is to reuse and manage the knowledge by renovating the knowledge resulting from the educational experiences as formed by teaching faculties in advanced education. In order to achieve this, an approach is being proposed that enhances the efficiency of knowledge sources by shaping and accomplishing decent exercises as well as its productivity which not only allows the reuse and management of knowledge effectively while it also boosts the quality of knowledge. We propose in the present work a three dimensional theoretical model of knowledge management and reuse (Figure 2(a) and Figure 2(b)) of Harsh [18, 21-24] based on the Nonaka and Takeuchi model (Figure 1) [1-5]. 
In the present work the features of higher education will be exploited in such a way that the concept of theoretical model of the knowledge management and knowledge reuse and its performance under different educational approaches are well clear to both staff and students. The outcomes of applying this methodology may be examined, charted by the argument and conclusions.

Knowledge management and reuse is centered on various activities like gathering, shaping, allocating by means of the academic resources of any institute. Such derived knowledge may be exploited to advantage the organizational members [26]. Evidently all actions related to knowledge management and reuse can be studied in terms of the knowledge transformation between institute's people [27]. Advancement of knowledge is associated with knowledge management [1-5] while the quality of knowledge is linked with the reuse of the knowledge [17, 18]. According to Roffe [11] higher education is an example of knowledge advancement while according to Weatherly [29] knowledge management involves the quality of services in the higher education. Thus the higher education tasks are parallel with the businesses [25].

Knowledge reuse is typically enhancing with the enhancement of novel shared applications within source and receiver [16]. Two Dimensional systems of Nonaka and Takeuchi [3] represent the renovations of tacit to explicit details as a result of socialization, externalization, combination and internalization procedures (see Figure 1). Knowledge distribution within the systems takes place over external information "and then converted back from information to knowledge" [3].

Higher education is a place where the revolution of knowledge continuously happens and where without the repetition of knowledge system cannot work. Point is that how it happens and how the separate entities of knowledge are responsible to participate in the knowledge conversion process? What type of actions needed to be implemented and how the quality of such system be kept always increasing? This issues forces us to think over a model which could not only cover the above facts while at the same time keeps the useful knowledge preserved over the time.

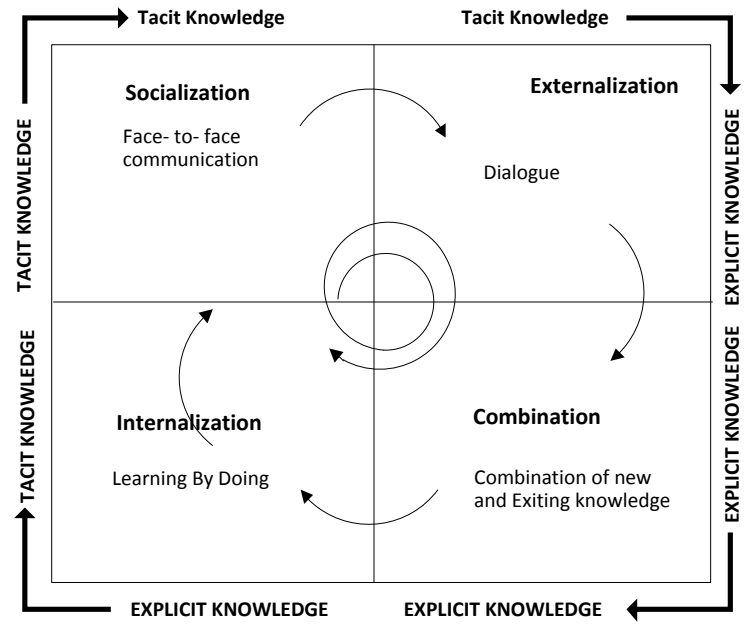

Fig. 1. Original Nonaka and Takeuchi Model [3]

\section{METHODOLOGY}

In the present investigation we undertake that dispersion of knowledge positively consumes time in an educational environment. It suggests that as time enriches entire knowledge of an institution changes. Genuine knowledge may also be improved by the process of repetitive reuse of knowledge. Since knowledge requires time to collect the information, to associate knowledge, to distribute knowledge from one system to another in a suitable shape. In this way the institute is continuously complemented the required knowledge.

Therefore, knowledge management issues in higher education can be dealt with the help of Nonaka and Takeuchi [1-5] and its extended models of Harsh [18, 21-24]. Keeping in mind the above aspects a three dimensional model of Harsh [21-24] which includes the concept of reusability at the start of the formation of the data and information [Harsh 18] is being offered in the present research to explore the knowledge management and knowledge reuse issues. Current study deals tacit, explicit and reusable knowledge as self-governing measures and explores a possibility to treat these quantities in an intense knowledge environment where conversion of knowledge from one form to another can significantly improve the knowledge management and knowledge reuse processes in an educational environment.

In the current research the extended three dimensional Knowledge Management models of Nonaka and Takeuchi [3] and Harsh et al. [18, 21-24, 30] have been engaged to appreciate the concept of reusability and its subsequent privilege. Using this model, a discussion on the knowledgesharing problems in numerous educational settings can also been offered.

Current suggestion is that rise in reusability surges knowledge in a three dimensional (see Figure 2 (a)) system over the processes of socialization, externalization, combination and internalization cycles (Figure 2(b)). Example is conversion of teaching of particular laboratory knowledge where every time we reuse the specific knowledge for the teaching exploration that is converting knowledge from Explicit to Explicit Forms (Due to Knowledge Reusability) (Low Complexity to High Complexity).

Added instance is translating knowledge from Explicit Forms to Tacit (as a result of Reusability) (High Complexity to High Complexity) that is transformation of Teaching Economic Management knowledge to teaching Supply Chain Management knowledge where the knowledge of Teaching of Economic Management (already be there so it is reusable) is transformed to knowledge of Teaching of Supply Chain Management.

\section{DETAILED INVESTIGATION}

Here it is notable that knowledge has been augmented adequately and added (with time) during the processes of three dimensional model (as matched to the two dimensional model) because of repetitive applications of knowledge reusability. Here we have considered another dimension as "knowledge reusability" (tacit and explicit). Current suggestion is that knowledge reusability is a vital chunk for an educational institute. Knowledge reusability always upsurges with the 
actual knowledge in an organization. Throughout the procedure of knowledge transformation, portion of the knowledge may be used for the purpose of reuse. Reusability of knowledge is possible for equally explicit and tacit both types of knowledge. Therefore, a distinct axis is needed to characterize the knowledge reusability. We previously recognized that the tacit and explicit both kinds of knowledge are reusable [21-24].

We suggest that both explicit and tacit knowledge are orthogonal (like in the earlier work [21-24]) to knowledge reusability whereas tacit and explicit both knowledge is reverse to each other. Enhancement of knowledge also takes place as a result of translation of one sort of the knowledge into the further (see Figures 2(a) and Figure 2 (b)). Thus by outspreading Nonaka and Takeuchi Model [3], it is possible to describe these revolutions by the subsequent rectilinear observation:

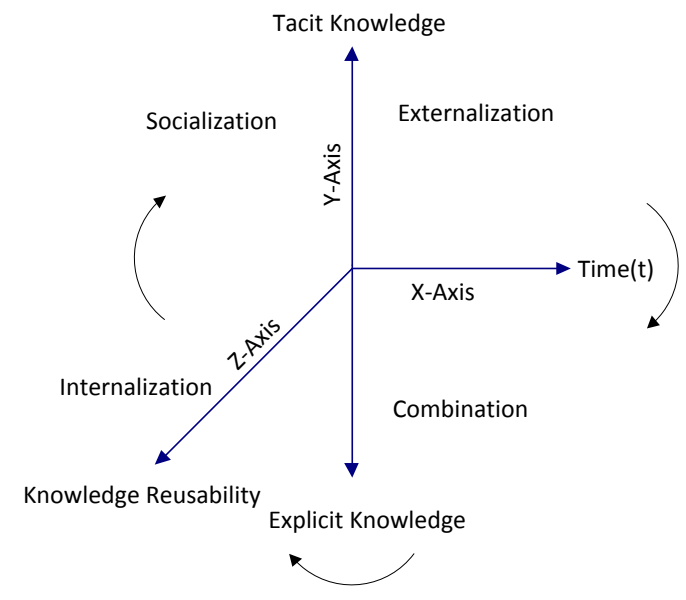

(a) Extended Nonaka and Takeuchi (1995) Model

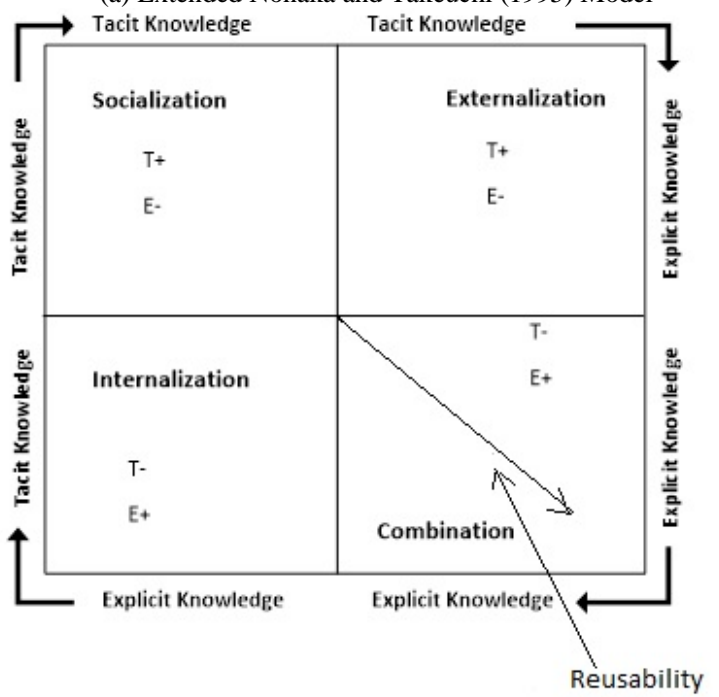

(b). Revised Nonaka and Takeuchi Model [1995]

Fig. 2. E-Refers to Explicit Knowledge and T-Refers to Tacit Knowledge that:

Refer to the Figure 2 (a) and 2(b) above, we accomplish
Socialization: This kind of process is the collaboration between individuals (Between teachers and students, between teachers and teachers as well as between students and students) and results in the sharing of tacit knowledge (Nonaka and Takeuchi Model [3]]). This process becomes evident since teachers can also share their reuse experiences over the time in addition to their other sort of experiences when they use their mental models and beliefs as well as perception. Due to such activities the knowledge within students' brains enhanced as a result of reusability of knowledge. Since Socialization comprise the transmission of tacit to tacit knowledge that is why it is represented in the left upper quadrant of the Figure 2 (a). In this quadrant such tacit knowledge is viewed as positive while the explicit knowledge is taken as negative. Discussion within students, teachers and among them during a teaching process may develop such kind of the knowledge. When such knowledge is repeated by a teacher within different classes and similar settings then the concept of reusability of such knowledge is very useful.

Externalization is the practice of bagging information about knowledge (Nonaka and Takeuchi Model [3]), for example teaching in a class, creating an article, sketching a Figure, making a presentation, or tutoring. These processes will be augmented more rapidly in the present case as compared with the associated with Nonaka and Takeuchi Model [3]. In this way there will be extra knowledge accessible to organization and moreover we will have more confidence in such knowledge because of replication of knowledge creates corrective or qualitative knowledge. Externalization comprises the translation of tacit into the explicit knowledge which is characterized in the upper right side of the quadrant in the Figure 2(a) and is extensively useful process for the teaching, tutoring and knowledge exchange processes in any educational organizations.

Combination makes tacit knowledge negative and the explicit knowledge positive. Means a teacher applies documented or text knowledge which was questioned by the students or by the administrative authorities of the organizations. Reusability of such knowledge will generate extra knowledge as the time enhances. These processes create a linkage as well as confidence between people in less time. Such knowledge may be linked with the already existing knowledge of the organization and may be reused whenever it is required.

It should be noted that both novel and current explicit knowledge have the substantial share in the knowledge combination procedure. It is interesting to note here that explicit knowledge is too transformed into the additional explicit knowledge which will be more useful or open for a given project.

Internalization is a process of accepting the information, tapping it into comfortable with one's own current knowledge (Nonaka and Takeuchi Model [3]). The Figures 2(a) and 2(b) reveal the knowledge conversion from explicit to tacit during numerous stages of knowledge distribution and reuse (like teaching by same or different teacher) during different time of the semester or the year. 
In real educational life the knowledge increases due to conversion from one form to another. It will be like a spiral as proposed by Nonaka and Takeuchi Model [3]. Such knowledge also involves reusability along with time. As a result of knowledge sharing (as the time enhances), (and translation of tacit into explicit knowledge) knowledge reusability of such also enhances in a given educational setting.

Notion of reuse is more logical than the notion of knowledge repetition (as proposed by Nonaka and Takeuchi Model [3]) as conferred above because we are not only interested about the way the knowledge upsurges while we are too interested about the entire upsurge of knowledge due to contribution of knowledge reusability and its importance to existing knowledge processes during teaching and tutoring.

Here we assume that the notion of ba's as projected by Nonaka, Toyama and Konno [4, 6] not simply continues the identical meaning while it also suitable for knowledge reusability in an educational environment. In the current research we are not changing the elementary features of Nonaka and Takeuchi Model [3] while somewhat we are spreading it by the addition of knowledge reusability (both for tacit and explicit knowledge) and explicit occurrence of time component (Figure 2 (a)). We describe a distinct axis to signify knowledge reusability which is the prerequisite for software engineering environment in a dynamic setting. Thus this model can be applied to teaching and learning processes where transformation and reuse of knowledge continuously takes place.

\section{OuTCOME}

In this way in the present work as a consequence of three dimensional knowledge model our system possesses six kinds of the knowledge management strategies (because of tacit and explicit knowledge) which are also termed as knowledge performance styles. These styles contribute in different ways to the knowledge reusability. Thus one can contemplate to consider a "Reusable Knowledge" (RK) space rather than only knowledge or K-space.

Thus the above three dimensional model is a broad knowledge illustration model through which it is conceivable not only to understand the teaching and learning processes by the conversion of tacit and explicit knowledge into each other while by the continuous conversion processes of tacit and explicit knowledge (spiral) can also accommodate all features of accessible knowledge in an educational environments as a result of varieties of different styles and modes of teachers in the class rooms. In addition, due to independent application of knowledge reusability, transformation of tacit to explicit knowledge and vice versa becomes quicker.

It should be noted that reusable component can be identified for the future applications and accordingly may be incorporated in the system which makes it easier to do the knowledge allocation. In addition to above we can also realize that as a consequence of present work Knowledge management advances from two fold to three fold and improves the trial solutions to decisive knowledge challenge and enriches not only the real knowledge of the institute while it may also support:

- Identifying qualitative knowledge as a result of applications of reusable knowledge components which will be highly useful in an educational research environment.

- Identifying and separating useful tacit and explicit knowledge required in a particular teaching and learning process.

- Quantifying and separating the knowledge components effectively to understand a process for given educational settings.

- Such system delivers faster knowledge in less time in any give educational environment.

Certainly a case study is essential on a particular system in order to realize the applications of reusability in an educational knowledge environment.

\section{KNOWLEDGE MANAGEMENT IN SOFTWARE ENGINEERING AND OUR PRESENT MODEL}

Both tacit and explicit knowledge play significant role during the software engineering processes. Thus the related reusable knowledge has a vital role in the development of new software. Reusable knowledge always play significant role in enhancing the software quality since repeated reusability helps in correcting the past mistakes and outcome. However, it is not necessary that we always employ the useful reusable knowledge during a particular process therefore identification of useful reusable components are essential.

According to Shull et al. [20] the Knowledge sharing subjects are very useful in the experimental software engineering. Tacit knowledge which is not coded is useful for experimental software engineering. Such knowledge requires reusability to reproduces the same quality.

Most people believe that the tacit knowledge is significant for experiment because this is a kind of knowledge that is not mentioned in the lab suite. Areas of socialization and internalization had the difficulties because of problem encountered in transferring the tacit knowledge. However, in the present case the application of reusability can resolve this issue to certain extent because reusable tacit knowledge can be easily transferred with the great confidentiality.

Dingsoyr and Conradi [19] work during the investigation of case studies of the usage of knowledge management in software productions observed the magnificent advantages like better job conditions for the developers of software. Educational environment will also have the application of the software which involves high degree of reusability issues. Knowledge sharing issues in an educational environment is very often which becomes more frequently and smoothly during the iterative process of reuse. Identification of software component is required to further develop the reusable software and to achieve wide ranging benefits. This type of system will be more precise, comprehensible and permits us to adapt more tacit knowledge into explicit knowledge with fewer efforts. 


\section{CONCLUSIONS}

An effort has been made in the present work to find out analytically that how tacit and explicit knowledge along with their respective reuse are useful in an educational environment.

Thus present work may help us in constituting and developing an educational system through which reusable knowledge components may deliver noteworthy reuse benefits and strategies in terms of well-defined tacit and explicit knowledge.

Present work can also assists in the management of the educational reusable knowledge components with respect to time where the quality of the system is a paramount.

\section{ACKNOWLEDGMENT}

The author (Sanjiv Sharma) is grateful to Prof O. K Harsh, Supervisor and Pro Chancellor of Glocal University for his constant encouragement, guiding and helping. The author would like to thanks to the Dean of the Ibra College of Technology for the support.

\section{REFERENCES}

[1] I. Nonaka, 'A dynamic theory of organizational knowledge creation'. Organization Science, 5, 1, 14-37 (1994).

[2] I. Nonaka, P. Byosiere, C. Borucki and N. Konno, 'Organizational Knowledge Creation Theory: a first comprehensive test'.International Business Review, 3, 4, 337-351 (1994).

[3] I. Nonaka, \& H. Takeuchi The Knowledge-Creating Company: How Japanese Companies Create the Dynamics for Innovation. Oxford University Press, New York, NY (1995).

[4] I. Nonaka, R. Toyama and N. Konno, 'SECI, Ba, and leadership: a unified model of dynamic knowledge creation'. Long Range Planning, 33, 5- 34 (2000).

[5] I. Nonaka, R. Toyama, and P. Byosière, 'A theory of organizational knowledge creation: understanding the dynamic process of creating knowledge'. In M., Dierkes, A.B., Antel, J. Child and I. Nonaka (Eds), Handbook of organizational learning and knowledge. Oxford: Oxford University Press, 491-517 (2001a).

[6] Nonaka, I., and Takeuchi, H. (1995). The Knowledge-Creating Company. Oxford University Press, Oxford.

[7] I. Nonaka, 'creating order out of chaos: self- renewal in Japanese firms'. California Management Review, 15, No.3, 57- 73(1988a).

[8] I. Nonaka 'toward middle-up-down management: accelerating information creation. Sloan Management Review, 29, No.3, 9- 18, (1988b).

[9] S. N. Gourlay, The SECI model of knowledge creation: some empirical shortcomings, in F. McGrath, and D. Remenyi, (eds), Fourth European Conference on Knowledge Management, Oxford, 18-19 September, pp. 377-385 (2003).

[10] R. Jorna, "Managing knowledge", Semiotic Review of Books, 9(2) (1998), http://www.chass.utronto.ca/epc/srb/managingknow.html (accessed 17 sept (2000).

[11] Roffe, I. M. (1998). Conceptual problems of continuous quality improvement and innovation in higher education, Quality Assurance in Education, 6(2), pp. 74-82.
[12] García-Peñalvo, F. J. (2011). La Universidad de la próxima década: La Universidad Digital. In C. Suárez- Guerrero \& F. J. García-Peñalvo (Eds.), Universidad y Desarrollo Social de la Web (pp. 181-197). Washington DC, USA: Editandum.

[13] Hinds, P. J., Patterson, M., and Pfeffer, J. (2001). Bothered by abstraction: The effect of expertise on knowledge transfer and subsequent novice performance, Journal of Applied Psychology, 86, pp. $1232-1243$.

[14] Davenport, T. H., and Prusak, L. (1998). Working knowledge: How organizations manage what they know, MA: Harvard Business School Press, Boston.

[15] R. M. Grant, Prospering in dynamically competitive environments: Organizational capabilities as knowledge integration. Organ. Sci.7 (4) 375-387(1996).

[16] L., P. Argote, Ingram, Knowledge transfer: A basis for competitive advantage in firms. Organ. Behavior Human Decision Processes 82(1), 150-169 (2000).

[17] O. K. Harsh, and A.S.M. Sajeev, Component Based Explicit Reuse. Engineering Letters, 13:1, EL_13_1_4 (Advance online publication): 4 May ( 2006)

[18] O. K. Harsh, Data, Information and Knowledge \& Reuse Management Techniques, World Congress of Engineering held at London from Jul 2 to 4 , (2007).

[19] ORGEIR DINGSOYR and REIDAR CONRADI, "A Surve of Case Studies of the Use of Knowledge Management in Software Engineering", Int Journal of Software Engineering and Knowledge Engineering, 112, No 4, 391-414. (2002).

[20] Shull, F., Mendoncça, M.G., Basili, V. et al. Knowledge-Sharing Issues in Experimental Software Engineering Empirical Software Engineering (2004) 9: 111.

[21] O. K. Harsh, Three Dimensional Explicit Knowledge Management and Reuse. Presented in International Conference on Knowledge Management in Organization. held in Lecee, Italy, Sept 10-11, 2007.

[22] O.K. Harsh, Three Dimensional Knowledge Management and Explicit Knowledge Reuse", Journal of Knowledge Management Practice, 10 (2), 2009. Available at: http://www.tlainc.com/articl187.htm.

[23] O. K. Harsh, Involvement of Tacit and Explicit Knowledge and its Management during Qualitative Learning in a Software Engineering Environment., International Journal of Software and Web Sciences (IJSWS), ISSN (Print): 2279-0063, ISSN (Online): 2279-0071, Issue 7, Volume 1 \& 2, December 2013-February-2014.

[24] O. K. Harsh, Role of Knowledge Reusability in Technological Environment during Learning. (IJACSA) International Journal of Advanced Computer Science and Applications, 5 (8), 2014.

[25] Al-Husseini, S., and Elbeltagi, I. (2015). Knowledge Sharing Practices as a Basis of Product Innovation: A Case of Higher Education in Iraq, International Journal of Social Science and Humanity, 5(2), pp. 182-185.

[26] Tseng, F.-C., and Kuo, F.-Y. (2014). A study of social participation and knowledge sharing in the teachers' online professional community of practice, Computers \& Education, 72, pp. 37-47.

[27] Bartol, K., and Srivastava, A. (2002). Encouraging knowledge sharing: The role of organizational reward systems, Journal of Leadership and Organizational Studies, 9(1), pp. 64-76.

[28] G. Szulanski, The process of knowledge transfer: A diachronic analysis of stickiness. Organ. Behavior Human Decision Processes 82(1), 9-27 (2000).

[29] Weatherly, L. A. (2003). The value of people: the challenges and opportunities of human capital measurement and reporting, Res. Q., 123, pp. 1-11. 